\title{
The Effect of Histological CD20-Positive B Cell Infiltration in Acute Cellular Rejection on Kidney Transplant Allograft Survival
}

\author{
Yan Jiang, ${ }^{1,2,3}$ Rending Wang, ${ }^{1,2,3}$ Huiping Wang, ${ }^{1,2,3}$ Hongfeng Huang, ${ }^{1,2,3}$ \\ Wenhan Peng, ${ }^{1,2,3}$ Wenxian Qiu, ${ }^{1,2,3}$ Jingyi Zhou, ${ }^{1,2,3}$ and Jianghua Chen ${ }^{1,2,3}$ \\ ${ }^{1}$ Kidney Disease Center, The First Affiliated Hospital, College of Medicine, Zhejiang University, Hangzhou, China \\ ${ }^{2}$ Key Laboratory of Kidney Disease Prevention and Control Technology, Zhejiang Province, China \\ ${ }^{3}$ The Third Grade Laboratory under the National State, Administration of Traditional Chinese Medicine, Hangzhou 310003, China
}

Correspondence should be addressed to Jianghua Chen; chenjianghua@zju.edu.cn

Received 23 September 2016; Accepted 16 November 2016

Academic Editor: Mepur H. Ravindranath

Copyright (c) 2016 Yan Jiang et al. This is an open access article distributed under the Creative Commons Attribution License, which permits unrestricted use, distribution, and reproduction in any medium, provided the original work is properly cited.

\begin{abstract}
Background. It is controversial whether lymphocyte infiltration exhibited in biopsy specimens is associated with transplant outcomes. This study focused on the effect of CD20-positive B cell infiltration in biopsy specimens from allografts with acute cellular rejection (ACR) in a Chinese population. Methods. Altogether, 216 patients transplanted from Sep. 2001 to Dec. 2014 with biopsy-proved ACR (Banff I or Banff II) were included in the analysis. Biopsies were immunostained for CD20 and C4d. Baseline information, serum creatinine and GFR before and after treatment, steroid resistance, response to treatment, graft loss, and survival were analyzed. Results. Eighty-three patients were classified into CD20-negative group, and 133 patients were classified into CD20positive group. Significantly more CD20-negative patients $(49 / 83,59.0 \%)$ received steroid plus antibody therapy compared with the CD20-positive group $(52 / 133,39.1 \%)(P=0.004)$. The response to treatment for ACR did not differ between these two groups. The CD20-positive group had less graft loss $(18.8 \%$ versus $32.5 \%, P=0.022)$ and a better graft survival rate. Further exploration of the infiltration degree suggested that it tended to be positively related to graft survival, but this did not reach statistical significance. Conclusion. CD20-positive B cell infiltration in renal allograft biopsies with ACR is associated with less steroid resistance and better graft survival. The presence of CD20-positive B cells is protective for renal allografts.
\end{abstract}

\section{Introduction}

Acute rejection (AR) is a major risk factor for chronic allograft nephropathy and renal allograft failure after kidney transplantation [1]. The Banff classification criteria divided AR into acute cellular rejection (ACR) and acute humoral rejection [2]. ACR is also known as "T cell mediated rejection," as it is associated with cytotoxic T cell infiltration. However, long-term allograft survival has not been completely improved by controlling factors that affect the $\mathrm{T}$ cell pathway [3-5]. In addition to $\mathrm{T}$ cells, other inflammatory cells, including CD20-positive B cells [6-8], plasma cells [911], macrophages [12-15], eosinophils [16-18], and NK cells [19], can also infiltrate grafts in ACR and may affect the severity of rejection and the therapeutic response.
The role of CD20-positive B lymphocytes in renal allograft biopsy specimens is still controversial. Using DNA microarrays and immunohistochemical staining, Sarwal et al. reported the presence of CD20-positive B lymphocytes in the graft interstitium of pediatric recipients with ACR for the first time, and they concluded that it was strongly associated with clinical glucocorticoid resistance and graft loss [7]. Subsequently, Hippen et al. classified ACR biopsies into the CD20-positive group if they demonstrated strong and diffuse staining characteristics, while trace or rare CD20positivity was recognized as the CD20-negative group [6]. Their research suggested that CD20-positive infiltrates correlated with worse clinical outcomes. Other studies also suggested a correlation between CD20 graft infiltration and steroid-resistant rejection [20, 21]. However, relevant studies 
TABLE 1: Distribution of Banff diagnosis stratified by CD20 staining.

\begin{tabular}{lccc}
\hline $\begin{array}{l}\text { Type } \\
\text { (grade) }\end{array}$ & $\begin{array}{c}\text { CD20-negative } \\
(n=83)\end{array}$ & $\begin{array}{c}\text { CD20-positive } \\
(n=126)\end{array}$ & $P=0.002$ \\
\hline IA & 30 & 65 \\
IB & 3 & 13 & \\
IIA & 45 & 34 \\
IA + IIA & 3 & 13 \\
IB + IIA & 1 & 5 \\
IA + IIB & 0 & 2 \\
IIB & 1 & 1 \\
\hline
\end{tabular}

have argued that CD20-positive B cells exhibited in biopsies have no effect on clinical outcome [22, 23]. Clatworthy et al. conducted a clinical trial comparing rituximab (an antiCD20 monoclonal antibody) with daclizumab (an anti-CD25 monoclonal antibody) as induction therapy in nonsensitive kidney transplant recipients, but this trial was suspended because of an excess incidence of ACR in the rituximab group [24]. The authors surmised that this anti-CD20 monoclonal antibody might have cleared immunoregulatory B cells, including B cells in the allograft tissue, which led to a marked increase in ACR. Disagreements that exist in published studies may be because of a relatively small sample size and lack of a unified standard for the definitions of what is CD20positive and CD20-negative.

The aim of this study was to determine the effects of CD20-positive B cell graft infiltration during ACR on allograft outcome in a Chinese population.

\section{Patients and Methods}

2.1. Patients. This is a retrospective study of patients who underwent kidney transplantation between September 2001 and December 2014 at the Kidney Disease Center of the First Affiliated Hospital of Zhejiang University (Hangzhou, China). This study was approved by the Committee of Ethics in Biomedical Research of Zhejiang University. Pathological records, clinical data, test results, and follow-up information of all patients were collected from the electronic medical record system and the kidney transplantation database of our center.

Altogether, 217 patients were identified with biopsyproven ACR (grade I or II) according to the Banff 2005 criteria and were negative for C4d staining. Excluding one patient who was lost of follow-up after antirejection treatment, 216 patients were included in this analysis. All patients were followed up until June 30, 2015. According to the presence of CD20-positive B cell infiltration, 83 recipients were classified into the CD20-negative group, and 133 were classified into the CD20-positive group. The pathologic types of ACR in these two groups were listed in Table 1.

Most of the recipients received calcineurin inhibitor (CNI) (cyclosporine or tacrolimus) in combination with mycophenolate mofetil (MMF) and steroids as maintenance immunosuppressive regimen, while some received rapamycin in place of CNI. Cyclosporine (CsA) was initiated at $5 \mathrm{mg} / \mathrm{kg} / \mathrm{d}$ and tacrolimus (FK506) at $0.10-0.15 \mathrm{mg} / \mathrm{kg} / \mathrm{d}$. The drug dosage was adjusted according to the plasma concentration. The target plasma concentration for CsA and FK506 was 250-300 $\mu \mathrm{g} / \mathrm{L}$ and 8-12 $\mu \mathrm{g} / \mathrm{L}$, respectively, during the first month after transplantation; $200-250 \mu \mathrm{g} / \mathrm{L}$ and 6$10 \mu \mathrm{g} / \mathrm{L}$, respectively, from the second to the third month; $150-200 \mu \mathrm{g} / \mathrm{L}$ and $4-8 \mu \mathrm{g} / \mathrm{L}$, respectively, from the fourth to the sixth month; and around $150 \mu \mathrm{g} / \mathrm{L}$ and $3-6 \mu \mathrm{g} / \mathrm{L}$, respectively, after the sixth month. MMF was started at 1.5$2 \mathrm{~g} / \mathrm{d}$ for half a month and maintained at $1 \mathrm{~g} / \mathrm{d}$ thereafter. Methylprednisolone was given at $6 \mathrm{mg} / \mathrm{kg}$ on the third postoperative day. Since then, starting from $80 \mathrm{mg} / \mathrm{d}$, with a daily reduction of $10 \mathrm{mg}$, prednisone was maintained at $10-$ $15 \mathrm{mg} / \mathrm{d}$.

Once acute rejection was proven by allograft biopsy, intravenous methylprednisolone was administrated at $6-10 \mathrm{mg} / \mathrm{kg}$ daily for 3 days as pulse therapy. If the serum creatinine $(\mathrm{Cr})$ level decreased more than $50 \%$ or went back to the baseline level within 1-2 weeks, the treatment was considered effective. If not, ACR was further treated with OKT3 at 5-10 mg/d or ATG at 100-200 mg/d for 5-7 days. Response to therapy was determined by comparing the serum Cr level measured two weeks after completion of the antirejection treatment to the baseline serum Cr level measured before rejection [25]. Response was considered complete if a decrease in serum $\mathrm{Cr}$ level was maximally $125 \%$ of baseline and partial if the $\mathrm{Cr}$ was $125 \%-175 \%$ of baseline, and it is no-response if $\mathrm{Cr}$ was still more than $175 \%$ of the baseline or graft loss (back to dialysis or nephrectomy).

2.2. Allograft Biopsy and Histopathology. Percutaneous ultrasound-guided renal biopsy was performed in recipients experiencing allograft dysfunction. Kidney allograft pathology diagnosis was made by an experienced renal pathologist (W. H.) according to the Banff 2005 criteria. We only included ACR grade I and grade II. ACR grade III and antibodymediated rejection were excluded. Vascular rejection refers to the existence of intimal arteritis in the ACR sample, that is, grades IIA, IIB, IIA + IA, IIA + IB, IIB + IA, and IIB + IB, according to the Banff 2005 criteria.

Immunohistochemical staining for CD20 and C4d was routinely performed on paraffin sections using the CD20 monoclonal antibody from Zhongshan (Cat number ZA0549, Beijing, China) and the C4d polyclonal antibody from Abcam (Cat number ab36075, Cambridge, UK). Using the same definition as those of Hippen et al., CD20-positive was defined as strong and diffuse staining characteristics, while trace or rare CD20-positivity was assigned to CD20-negative [6]. The CD20-positive specimens were further assessed independently by two authors (W. R. and W. H.) and defined as mild-positive if CD20-positive cells accounted for less than $25 \%$ of the inflammatory cells, moderate-positive if CD20positive cells were $26 \%-49 \%$ of the inflammatory cells, and severe-positive if CD20-positive cells were more than $50 \%$ of the inflammatory cells. Representative images are shown in Figure 1. All the patients included in this study were negative for C4d staining. 


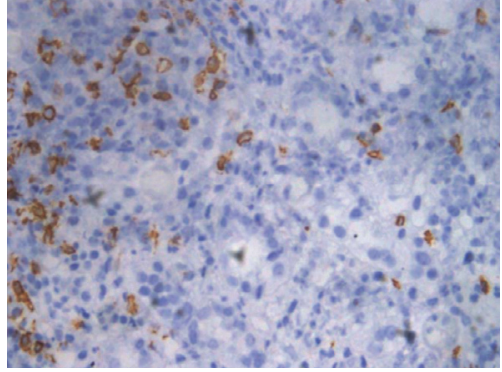

(a)

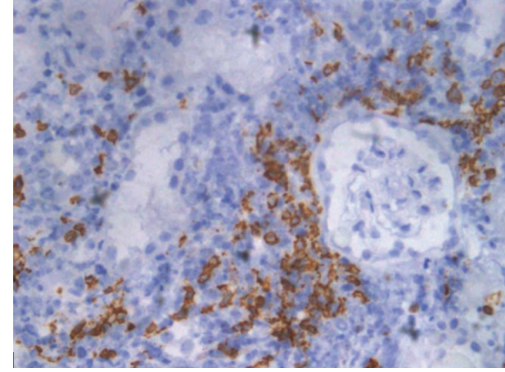

(b)

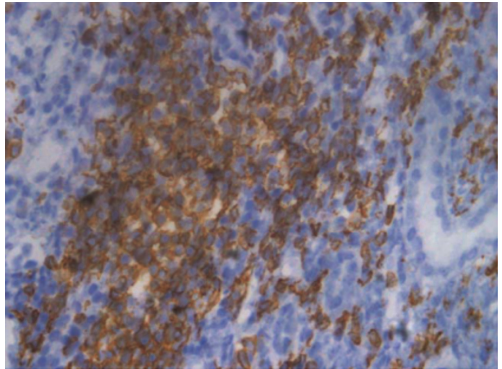

(c)

FIGURE 1: Representative pictures of CD20 immunostaining in ACR (×400): (a) CD20 mild-positive; (b) CD20 moderate-positive; (c) CD20 severe-positive.

2.3. Statistical Analysis. Continuous variables are expressed as mean \pm standard deviation (SD) or median (range). Categorical variables are presented as numbers (frequencies). Normally distributed continuous variables were analyzed using student's $t$-test or one-way ANOVA, and nonnormally distributed continuous variables were analyzed using Mann-Whitney test. Chi-square test was used for categorical variables. Graft/patient survival was analyzed with KaplanMeier method and differences between survival curves were calculated by the log-rank test. Factors associated with graft loss on the univariate analysis with $P<0.1$ were included into a Cox multivariate analysis. All statistical calculations used SPSS 19.0. Two sided $P<0.05$ was considered as significant difference.

\section{Results}

3.1. Baseline Characteristics. The baseline characteristics of the patients were listed in Table 2. Eighty-three patients were assigned to the CD20-negative group, and 133 patients were classified as CD20-positive. No significant differences in age, gender, cold/warm ischemia time, donor type, primary disease, induction regimen, and prerejection immunosuppressive drugs were observed between these two groups. ACR was diagnosed earlier after kidney transplantation in the CD20-negative group compared with CD20-positive group (median time to ACR, 29 days versus 142 days, $P=0.016$ ). As presented in Table 1, the pathologic types differed in two groups $(P=0.002)$. There was significantly more vascular rejection (IIA, IIB, IIA + IA, IIA + IB, IIB + IA, and IIB + IB) in the CD20-negative group (50/83 patients, $60.2 \%$ ), compared with the CD20-positive group (55/133 patients, 41.4\%) $(P=$ 0.005).

3.2. Antirejection Therapy. In general, CD20-negative patients presented with higher prerejection serum Cr levels, compared with the CD20-positive group $(180.1 \pm 128.4$ versus $130.6 \pm 68.1 \mu \mathrm{mol} / \mathrm{L}, P=0.002)$. The same results were obtained with peak $\mathrm{Cr}$ at rejection $(352.7 \pm 242.3$ versus $274.1 \pm 265.6 \mu \mathrm{mol} / \mathrm{L}, P=0.027)$. No significant differences were observed at any other time point during follow-up (Table 3). Corresponding to this, worse GFR was observed in the CD20-negative group before rejection $(47.2 \pm 21.3$ versus $60.4 \pm 21.6 \mathrm{~mL} / \mathrm{min}, P<0.001)$, and the same results were obtained at the time of rejection $(25.0 \pm 15.0$ versus $30.6 \pm 13.3 \mathrm{~mL} / \mathrm{min}, P=0.005)$. No significant differences between CD20-positive and CD20-negative groups were observed at any other time point during follow-up (Table 4).

Patients in the CD20-positive and CD20-negative groups received similar maintenance immunosuppressive regimen after rejection (Table 5). After ACR, significantly more CD20-negative patients $(49 / 83,59.0 \%)$ received steroid plus antibody therapy (defined as steroid-resistant rejection) compared with the CD20-positive group $(52 / 133,39.1 \%)(P=$ $0.004)$. The response to treatment for ACR did not differ between these two groups.

3.3. CD20 Staining and Patient/Graft Survival Rates. More patients in the CD20-negative group (27/83, 32.5\%) experienced graft loss compared with the CD20-positive group $(25 / 133,18.8 \%)$, which reached a significant difference $(P=$ 0.022 ). Figure 2 (a) displayed the graft survival over time analyzed by the Kaplan-Meier death-censored method for CD20-positive and CD20-negative groups. CD20-positive infiltration was associated with significantly better allograft survival $(P=0.049)$. There was no significant difference in the patient survival rate between these two groups.

3.4. Association of the Degree of CD20 Infiltration and Patient/Graft Survival. We further divided the CD20-positive group into CD20 mild-positive subgroup ( $n=76)$, CD20 moderate-positive subgroup $(n=36)$, and CD20 severepositive subgroup $(n=31)$ according to the percentage of CD20-positive B cells found in the inflammatory cell population. Figure 3(a) showed that the CD20 severe-positive subgroup tended to have better graft survival compared to the other three groups, but this difference was not significant. Patient survival was similar among these four groups (Figure $3(\mathrm{~b}))$.

3.5. Predictor of Graft Loss in a Cox Proportional-Hazards Model. Univariate analysis showed that the CD20-positive infiltration, prerejection immunosuppressive regimen, 
TABLE 2: Patient baseline characteristics stratified by CD20 staining.

\begin{tabular}{|c|c|c|c|}
\hline Characteristics & $\begin{array}{c}\text { CD20-negative } \\
(n=83)\end{array}$ & $\begin{array}{c}\text { CD20-positive } \\
\quad(n=133)\end{array}$ & $P$ value \\
\hline Sex (male/female) & $54 / 29$ & $94 / 39$ & 0.387 \\
\hline Age at transplantation (years) & $39.1 \pm 12.0$ & $37.5 \pm 11.5$ & 0.332 \\
\hline Warm ischemia time (min) & $5.5 \pm 1.9$ & $5.5 \pm 2.4$ & 0.657 \\
\hline Cold ischemia time (min) & $442 \pm 204$ & $448 \pm 209$ & 0.792 \\
\hline Donor type & & & 0.863 \\
\hline Living & $17(20.5 \%)$ & $26(19.5 \%)$ & \\
\hline Deceased & $66(79.5 \%)$ & $107(80.1 \%)$ & \\
\hline Primary disease & & & 0.445 \\
\hline Chronic nephritis & $75(90.4 \%)$ & $119(89.5 \%)$ & \\
\hline AKPD & $6(7.2 \%)$ & $5(3.8 \%)$ & \\
\hline Diabetic nephropathy & $0(0)$ & $2(1.5 \%)$ & \\
\hline Gouty nephropathy & $0(0)$ & $2(1.5 \%)$ & \\
\hline Hereditary nephropathy & $0(0)$ & $2(1.5 \%)$ & \\
\hline Others & $2(2.4 \%)$ & $3(2.2 \%)$ & \\
\hline Number of HLA mismatches & $3.11 \pm 1.22$ & $2.98 \pm 1.26$ & 0.468 \\
\hline Induction regimen & & & 0.498 \\
\hline CD25 monoclonal antibody & $35(42.2 \%)$ & $46(34.6 \%)$ & \\
\hline ATG/OKT3 & $4(4.8 \%)$ & $9(6.8 \%)$ & \\
\hline None & $44(53.0 \%)$ & $78(58.6 \%)$ & \\
\hline \multicolumn{4}{|l|}{ PRA $>10 \%$ - number $(\%)$} \\
\hline After transplant & $4(4.8 \%)$ & $2(1.5 \%)$ & 0.149 \\
\hline At rejection & $3(3.6 \%)$ & $5(3.8 \%)$ & 0.956 \\
\hline Prerejection immunosuppressant arms & & & 0.230 \\
\hline FK506 + MMF + Pred & $53(63.9 \%)$ & $76(57.1 \%)$ & \\
\hline $\mathrm{CSA}+\mathrm{MMF}+$ Pred & $27(32.5 \%)$ & $53(39.8 \%)$ & \\
\hline Rapamycin + MMF + Pred & $1(1.2 \%)$ & $2(1.5 \%)$ & \\
\hline $\mathrm{CSA}+$ rapamycin + Pred & $2(2.4 \%)$ & 0 & \\
\hline $\mathrm{CSA}+\mathrm{AZA}+$ Pred & $0(0)$ & $2(1.5 \%)$ & \\
\hline Median days to ACR (range) (days) & $29(3-3878)$ & $142(3-3398)$ & 0.016 \\
\hline
\end{tabular}

PRA, panel reactive antibody; AZA, azathioprine; CSA, cyclosporine; FK506, tacrolimus; MMF, mycophenolate mofetil; PRED, prednisone.

TABLE 3: Serum creatinine values during follow-up.

\begin{tabular}{lccc}
\hline & CD20-negative & CD20-positive & $P$ value \\
\hline Before rejection & $180.1 \pm 128.4(83)$ & $130.6 \pm 68.1(133)$ & 0.002 \\
Peak & $352.7 \pm 242.3(83)$ & $274.1 \pm 265.6(133)$ & \\
After biopsy & & & \\
$\quad 1$ month & $183.2 \pm 143.2(80)$ & $160.1 \pm 171.8(132)$ & 0.027 \\
3 months & $150.6 \pm 102.5(62)$ & $135.8 \pm 55.6(113)$ & 0.313 \\
6 months & $127.4 \pm 50.9(63)$ & $142.6 \pm 68.7(125)$ & 0.293 \\
12 months & $126.9 \pm 43.7(64)$ & $144.7 \pm 97.9(110)$ & 0.101 \\
24 months & $127.1 \pm 49.5(58)$ & $131.0 \pm 80.0(91)$ & 0.742 \\
36 months & $114.1 \pm 49.5(38)$ & $129.4 \pm 58.2(69)$ & 0.173 \\
48 months & $116.8 \pm 77.1(26)$ & $116.4 \pm 36.5(47)$ & 0.734 \\
60 months & $113.0 \pm 72.0(23)$ & & 0.788 \\
\hline
\end{tabular}


TABLE 4: GFR values during follow-up.

\begin{tabular}{llcc}
\hline & CD20-negative & CD20-positive & $P$ value \\
\hline Rerejection & $47.2 \pm 21.3(83)$ & $60.4 \pm 21.6(133)$ & $<0.001$ \\
Peak & $25.0 \pm 15.0(83)$ & $30.6 \pm 13.3(133)$ & \\
After Biopsy & & & \\
$\quad 1$ month & $47.2 \pm 21.8(80)$ & $52.5 \pm 19.8(132)$ & 0.005 \\
3 months & $54.0 \pm 20.2(62)$ & $55.6 \pm 19.4(113)$ & 0.641 \\
6 months & $58.5 \pm 18.1(63)$ & $54.8 \pm 20.6(125)$ & 0.224 \\
12 months & $58.1 \pm 19.8(64)$ & $57.3 \pm 22.7(110)$ & 0.804 \\
24 months & $58.2 \pm 17.4(58)$ & $60.6 \pm 23.7(91)$ & 0.502 \\
36 months & $66.7 \pm 25.0(38)$ & $69.8 \pm 20.5(69)$ & 0.123 \\
48 months & $69.3 \pm 24.1(26)$ & $64.1 \pm 21.4(47)$ & 0.212 \\
60 months & $68.3 \pm 20.3(23)$ & & 0.428 \\
\hline
\end{tabular}

TABLE 5: Antirejection therapy and response to treatment.

\begin{tabular}{lcc}
\hline & $\begin{array}{c}\text { CD20-negative } \\
(n=83)\end{array}$ & $\begin{array}{c}\text { CD20-positive } \\
(n=133)\end{array}$ \\
\hline $\begin{array}{l}\text { Postrejection immunosuppressant arms } \\
\text { FK506 + MMF + Pred }\end{array}$ & $113(85.0 \%)$ \\
CSA + MMF + Pred & $69(83.1 \%)$ & $18(13.5 \%)$ \\
Rapamycin + MMF + Pred & $13(15.7 \%)$ & $2(1.5 \%)$ \\
Antirejection therapy & $1(1.2 \%)$ & $81(60.9 \%)$ \\
Steroids & & $52(39.1 \%)$ \\
Steroids + antibody & $34(41.0 \%)$ & 0.004 \\
Response to treatment & $49(59.0 \%)$ & $86(64.7 \%)$ \\
Complete & & $28(21.0 \%)$ \\
partial & $55(66.2 \%)$ & $19(14.3 \%)$ \\
No response & $11(13.3 \%)$ & 0.232 \\
\hline
\end{tabular}

TABLE 6: Cox regression hazard ratios for renal allograft failure.

\begin{tabular}{|c|c|c|c|c|c|c|}
\hline & \multicolumn{3}{|c|}{ Univariate } & \multicolumn{3}{|c|}{ Multivariate } \\
\hline & $\mathrm{RR}$ & $95 \%$ CI & $P$ & $\mathrm{RR}$ & $95 \% \mathrm{CI}$ & $P$ \\
\hline CD20-positive infiltrates & 0.506 & $0.293-0.872$ & 0.014 & 0.570 & $0.327-0.995$ & 0.048 \\
\hline Prerejection immunosuppressive regimen & 0.392 & $0.221-0.696$ & 0.001 & 0.621 & $0.356-1.083$ & 0.093 \\
\hline Antirejection therapy (combination versus MMP) & 3.142 & $1.724-5.728$ & $<0.001$ & 3.316 & $1.677-5.958$ & $<0.001$ \\
\hline Response to treatment & & & $<0.001$ & & & $<0.001$ \\
\hline Partial versus complete response & 2.613 & $1.129-6.048$ & 0.025 & 2.538 & $1.078-5.974$ & 0.033 \\
\hline No-response versus complete response & 13.410 & $7.032-25.570$ & $<0.001$ & 13.847 & $7.018-27.321$ & $<0.001$ \\
\hline
\end{tabular}

$\mathrm{RR}$, relative risk; $\mathrm{CI}$, confidence interval.

antirejection therapy, and antirejection response were the factors influencing renal allograft loss. Further multivariate Cox regression analysis revealed that CD20 infiltration was a protective factor for graft loss. Antirejection therapy is another independent risk factor. The adjusted risk ratio of graft loss for steroid plus antibody treatment was 2.316 compared with steroid alone. Compared with the complete response, the adjusted risk ratio of graft loss was 2.538 for partial-response and 13.847 for no-response, as exhibited in Table 6. The prerejection immunosuppressive regimen, which was significant in the univariate analysis, did not reach significance in the multivariate analysis.

\section{Discussion}

Our study demonstrated that CD20-positive infiltration in the biopsy specimens from the allografts with ACR was associated with less steroid-resistant rejection and better allograft survival. Further exploration of the infiltration degree suggested that it tended to be positively related with graft 


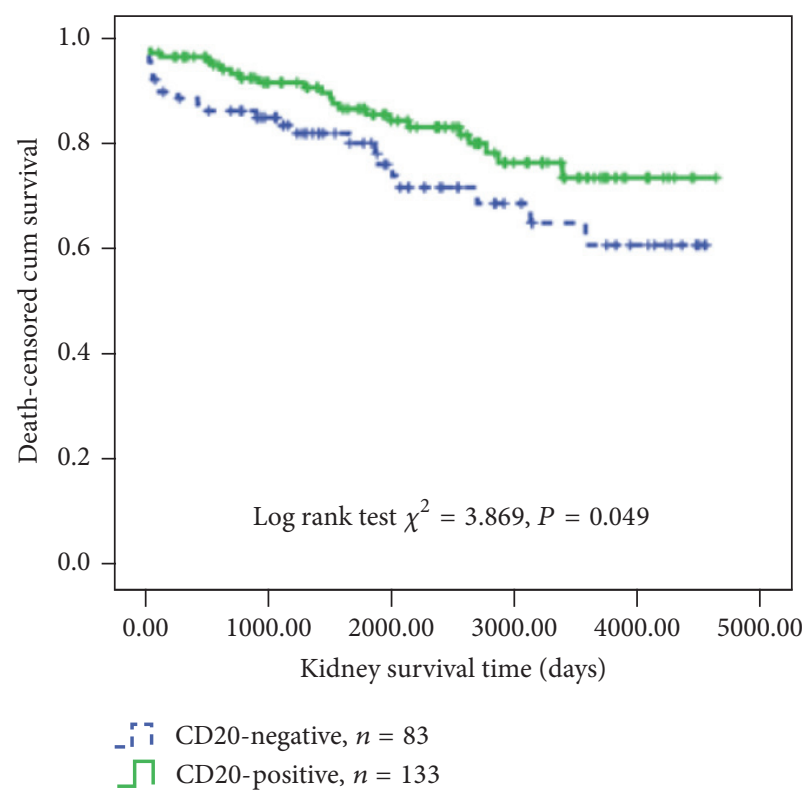

(a)

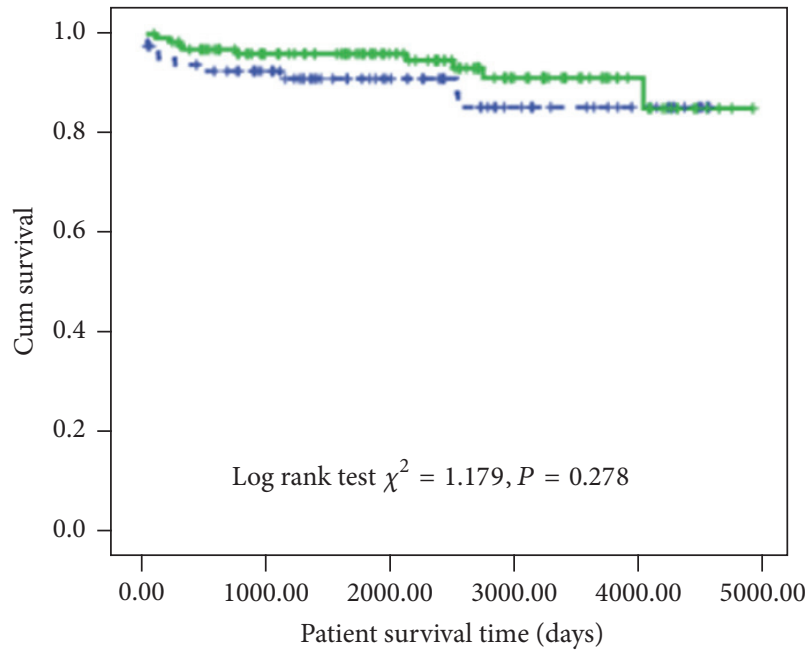

- i c CD20-negative, $n=83$

$\sqcap$ CD20-positive, $n=133$

(b)

FIGURE 2: Effects of CD20 staining on (a) death-censored renal allograft survival; (b) patient survival.

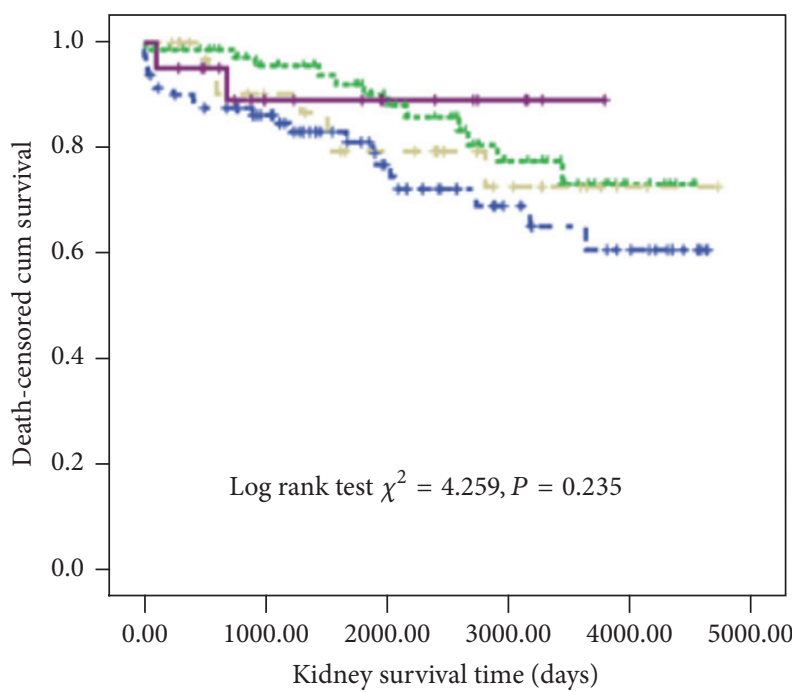

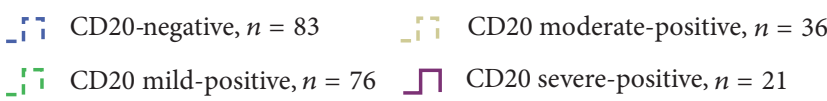

(a)

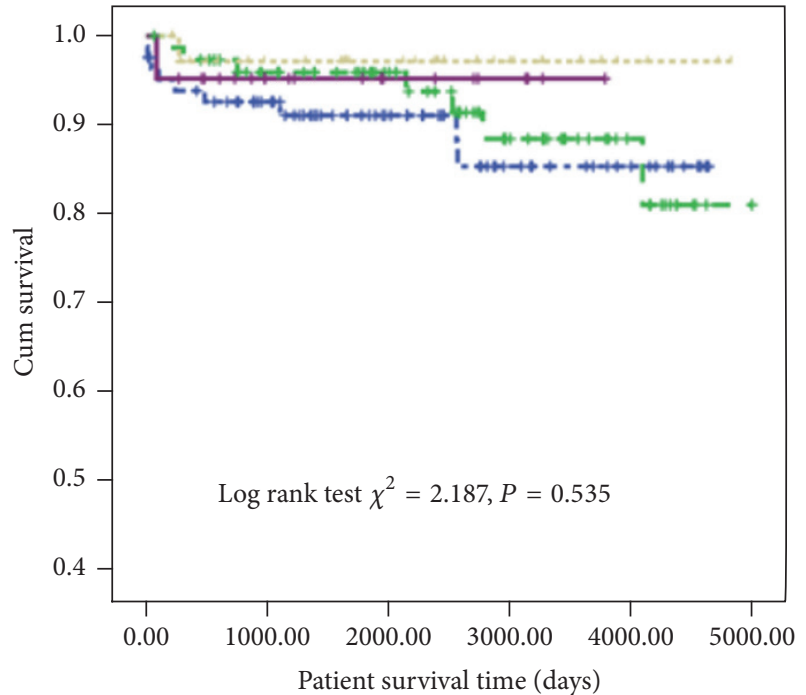

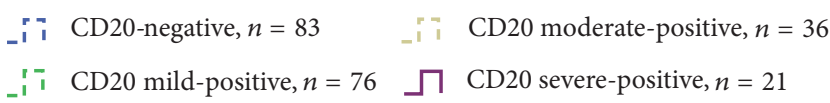

(b)

FIGURE 3: Effects of CD 20 infiltration degrees on (a) death-censored renal allograft survival; (b) patient survival.

survival, but without statistical significance. Multivariate Cox regression revealed that $\mathrm{CD} 20$-positive infiltration, antirejection therapy, and antirejection response were independent predictors of graft loss. The presence of CD20-positive B cells was a protective factor for graft loss.

$\mathrm{B}$ cells are very common in solid organ transplantation. B cells and plasma cells in pathological tissues have been considered as nonspecific effector cells in the past $[26,27]$. In 2003, Sarwal et al. first demonstrated the presence of CD20-positive B cells in the graft interstitium of pediatric transplant recipients experiencing ACR [7]. Their study suggested that CD20-positive infiltration was associated with steroid-resistant rejection and worse graft survival. Since then, the role of CD20-positive B cells in ACR has attracted more attention. In adult kidney transplantation, $22 \%$ of acute rejection (IA, IB) specimens had CD20-positive infiltration, and it was associated with worse outcome [6]. A mouse model of acute cardiac allograft 
rejection demonstrated that recipients' B cells participate in indirect alloantigen presentation and play an important role in the progression of acute vascular rejection [28]. Studies analyzing the CD20-positive $\mathrm{B}$ cells' infiltration pattern in adult kidney transplantation reported higher serum Cr levels in recipients with clusters of B cells [29]. Some studies have suggested that once recruited into injured grafts, B cells can act as antigen-presenting cells to promote $\mathrm{T}$ cell mediated rejection, which is resistant to conventional steroid therapy [30].

Different result was observed, suggesting that the early infiltration of B cells can be beneficial $[23,31]$. Scheepstra et al. performed immunostaining for CD20 on 54 biopsyproven ACR samples, and no correlation was found between the number of CD20 cells, in clusters or in a scattered pattern, and clinical outcome [23]. Increased peripheral blood B cells were detected in the steady recipients [32], instead of those experiencing rejection. CD20 transcription was found to be increased in tolerant kidney transplant recipients [3335]. Kayler et al. suggested that $B$ cells were not indicators of graft loss or steroid resistance in their analysis of 120 ACR biopsies [36]. This result was proved by other studies [37].

Thus, the role of CD20-positive B lymphocytes in acute cellular rejection is controversial. One of the possible explanations for this is the lack of a unified standard on the definition of CD20-positive and CD20-negative. Sarwal and her colleagues defined CD20-positive as more than 275 CD20-positive cells in a single high power field (HPF) and came to the conclusion that CD20-positive cells were strongly associated with severe graft rejection [7]. Hippen et al. used a qualitative method in their research and defined biopsies with strong and diffuse staining characteristics of CD20-positive cells as the CD20-positive group, while trace or rare CD20positive cells were recognized as the $\mathrm{CD} 20$-negative group [6]. Their research indicated that CD20-positive infiltration was more likely to have steroid-resistant rejection and worse graft survival. In Bagnasco's research, CD20-positive patients (at least one cluster containing more than 100/HPF CD20positive cells) and CD20-negative patients (the count was below 50/HPF) were compared [37]. No association was found between CD20-positive infiltrates and worse graft outcome using this method. CD20-positive lymphoid clusters, which were defined as any dense cluster of lymphoid cells containing more than 15 CD20-positive B cells by Kayler et al., did not predict steroid resistance or worse graft survival [36].

The definition of CD20-positive and CD20-negative in our study is in line with Hippen et al's research. However, our study's findings that CD20-positive infiltration is associated with better clinical outcomes are not consistent with Hippen et al.'s results [6]. Differences exist between our two studies. First, our study included a larger number of ACR biopsies than any published studies so far. A total of 216 cases of biopsy-proven ACR were included in our analysis; 83 samples were assigned to the CD20-negative group, and 133 were classified as CD20-positive. Hippen et al.s study cohort contained 27 patients and only 6 biopsies were classified as CD20positive. As mentioned in the discussion by the authors, the relative small sample sizes in their analysis may limit the generalization of their conclusions. Secondly, Hippen et al's research was conducted in biopsies with proven Banff IA or IB rejection within the first year after transplantation. Our study included patients with ACR grade I and grade II at any time point after kidney transplantation. The differences in the inclusion criteria of study population may contribute to the different results. Similarly, Scheepstra et al. [23] adopted the same method to assess CD20-positive as mentioned in Sarwal et al.s work [7], but they reported different results. Thus, besides the lack of a uniformed definition of CD20positive and CD20-negative, a relatively small sample size, different study populations (pediatrics versus adults; different subgroups of ACR), differences in the induction and maintenance immunosuppression therapy, different follow-up durations, and other factors can contribute to the inconsistency in the studies concerning the role of CD20-positive infiltration in ACR.

The prognostic study of CD20-positive cells in ACR helps to select future treatment, in particular, whether or not to apply B-cell-depleting agents in steroid-resistant rejection. Rituximab, an anti-CD20 monoclonal antibody, was first applied in the treatment of lymphoma. It has been proven effective in treatment of a number of hematological diseases and autoimmune diseases [38-40]. In the aspect of transplantation, rituximab has been used for desensitization of panel reactive antibody, anti-HLA antibody, and anti-ABO antibody before transplantation as induction regimen and treatment of humoral rejection after transplantation [41-47]. In 2002, a cardiac transplant patient with vascular rejection refractory to plasmapheresis was successfully treated with rituximab, which was the first documented application of an anti-CD20 monoclonal antibody in the aspect of rejection [48]. Later, other case reports confirmed that CD20 monoclonal antibody was effective in the treatment of vascular rejection in heart and pancreas transplantation [49-51]. At present, rituximab is applied to treat steroidresistant rejection after renal transplantation. It can clear DSA and B cells to improve outcomes after renal allograft rejection [52]. After treatment, the reconstruction of peripheral B cells requires 6 to 9 months. The CD20-positive B cells in graft are significantly reduced after treatment, but the studies of the reconstruction of $\mathrm{B}$ cells in grafts are rather rare [53]. Our results showed that $\mathrm{CD} 20$-positive infiltration in patients with ACR appeared to have a protective effect on graft outcome. Additionally, a clinical trial which planned to use rituximab in nonsensitive kidney transplant recipients was forced to stop because of increases in rejection [24]. Thus, the administration of anti-CD20 monoclonal antibody in patients with ACR requires careful consideration.

\section{Conclusion}

CD20-positive B cell infiltration in renal allograft biopsies with ACR is associated with less steroid-resistant rejection and better graft survival. The presence of CD20-positive B cells is protective for renal allografts. 


\section{Competing Interests}

The authors declare that there is no conflict of interests regarding the publication of this paper.

\section{Authors' Contributions}

Yan Jiang and Rending Wang contribute equally to this paper.

\section{Acknowledgments}

This study was supported by Grants from Zhejiang Science and Technology Department 2012C13G2010133; Health and Family Planning Commission of Zhejiang province 2013KYB115; and National Natural Science Foundation of China 81370851.

\section{References}

[1] H.-U. Meier-Kriesche, A. O. Ojo, J. A. Hanson et al., "Increased impact of acute rejection on chronic allograft failure in recent era," Transplantation, vol. 70, no. 7, pp. 1098-1100, 2000.

[2] K. Solez, R. B. Colvin, L. C. Racusen et al., "Banff '05 meeting report: differential diagnosis of chronic allograft injury and elimination of chronic allograft nephropathy ('CAN')," American Journal of Transplantation, vol. 7, no. 3, pp. 518-526, 2007.

[3] M. D. Pescovitz, "B cells: a rational target in alloantibodymediated solid organ transplantation rejection," Clinical Transplantation, vol. 20, no. 1, pp. 48-54, 2006.

[4] J. Wu, J. Chen, Y. Wang et al., "Impact of acute rejection episodes on long-term renal allograft survival," Chinese Medical Journal, vol. 116, no. 11, pp. 1741-1745, 2003.

[5] J.-H. Chen, R.-D. Wang, J.-Y. Wu et al., "[The influence of early vascular rejection on late rejection in first cadaveric renal transplantation]," National Medical Journal of China, vol. 85, no. 5, pp. 332-334, 2005.

[6] B. E. Hippen, A. DeMattos, W. J. Cook, C. E. Kew II, and R. S. Gaston, "Association of CD20+ infiltrates with poorer clinical outcomes in acute cellular rejection of renal allografts," American Journal of Transplantation, vol. 5, no. 9, pp. 22482252, 2005.

[7] M. Sarwal, M.-S. Chua, N. Kambham et al., "Molecular heterogeneity in acute renal allograft rejection identified by DNA microarray profiling," New England Journal of Medicine, vol. 349, no. 2, pp. 125-138, 2003.

[8] E. W. Tsai, P. Rianthavorn, D. W. Gjertson, W. D. Wallace, E. F. Reed, and R. B. Ettenger, "CD20+ lymphocytes in renal allografts are associated with poor graft survival in pediatric patients," Transplantation, vol. 82, no. 12, pp. 1769-1773, 2006.

[9] P. I. Terasaki and J. Cai, "Humoral theory of transplantation: further evidence," Current Opinion in Immunology, vol. 17, no. 5, pp. 541-545, 2005.

[10] V. Gärtner, T. K. Eigentler, and R. Viebahn, "Plasma cell-rich rejection processes in renal transplantation: morphology and prognostic relevance," Transplantation, vol. 81, no. 7, pp. 986991, 2006.

[11] V. Nickeleit and K. Andreoni, "The classification and treatment of antibody-mediated renal allograft injury: where do we stand?" Kidney International, vol. 71, no. 1, pp. 7-11, 2007.

[12] H. Nomi, J. Tashiro-Yamaji, Y. Yamamoto et al., "Acute rejection of allografted CTL-susceptible leukemia cells from perforin/Fas ligand double-deficient mice," Journal of Immunology, vol. 179, no. 4, pp. 2180-2186, 2007.

[13] P. J. Matheson, I. D. Dittmer, B. W. Beaumont, M. J. Merrilees, and H. L. Pilmore, "The macrophage is the predominant inflammatory cell in renal allograft intimal arteritis," Transplantation, vol. 79, no. 12, pp. 1658-1662, 2005.

[14] A. D. Kirk, D. A. Hale, R. B. Mannon et al., "Results from a human renal allograft tolerance trial evaluating the humanized CD52-specific monoclonal antibody alemtuzumab (Campath1H)," Transplantation, vol. 76, no. 1, pp. 120-129, 2003.

[15] K. R. Wyburn, M. D. Jose, H. Wu, R. C. Atkins, and S. J. Chadban, "The role of macrophages in allograft rejection," Transplantation, vol. 80, no. 12, pp. 1641-1647, 2005.

[16] E. J. Barnes, M. M. Abdel-Rehim, Y. Goulis et al., "Applications and limitations of blood eosinophilia for the diagnosis of acute cellular rejection in liver transplantation," American Journal of Transplantation, vol. 3, no. 4, pp. 432-438, 2003.

[17] M. Surquin, A. Le Moine, V. Flamand et al., "IL-4 deficiency prevents eosinophilic rejection and uncovers a role for neutrophils in the rejection of MHC class II disparate skin grafts," Transplantation, vol. 80, no. 10, pp. 1485-1492, 2005.

[18] T. Wu, G. Bond, D. Martin, M. A. Nalesnik, A. J. Demetris, and K. Abu-Elmagd, "Histopathologic characteristics of human intestine allograft acute rejection in patients pretreated with thymoglobulin or alemtuzumab," The American Journal of Gastroenterology, vol. 101, no. 7, pp. 1617-1624, 2006.

[19] W. H. Kitchens, S. Uehara, C. M. Chase, R. B. Colvin, P. S. Russell, and J. C. Madsen, "The changing role of natural killer cells in solid organ rejection and tolerance," Transplantation, vol. 81, no. 6, pp. 811-817, 2006.

[20] A. Lehnhardt, M. Mengel, L. Pape, J. H. H. Ehrich, G. Offner, and J. Strehlau, "Nodular B-cell aggregates associated with treatment refractory renal transplant rejection resolved by rituximab," American Journal of Transplantation, vol. 6, no. 4, pp. 847-851, 2006.

[21] M. Alausa, U. Almagro, N. Siddiqi, R. Zuiderweg, R. Medipalli, and S. Hariharan, "Refractory acute kidney transplant rejection with CD20 graft infiltrates and successful therapy with rituximab," Clinical Transplantation, vol. 19, no. 1, pp. 137-140, 2005.

[22] C. C. Nast, A. Moudgil, X.-J. Zuo, A. Wilkinson, G. M. Danovitch, and S. C. Jordan, "Cyclosporine microemulsionand mycophenolate mofetil-related lymphoid aggregates are not associated with acute rejection," Transplantation, vol. 72, no. 2, pp. 251-256, 2001.

[23] C. Scheepstra, F. J. Bemelman, C. Van Der Loos et al., "B cells in cluster or in a scattered pattern do not correlate with clinical outcome of renal allograft rejection," Transplantation, vol. 86, no. 6, pp. 772-778, 2008.

[24] M. R. Clatworthy, C. J. E. Watson, G. Plotnek et al., "B-celldepleting induction therapy and acute cellular rejection," New England Journal of Medicine, vol. 360, no. 25, pp. 2683-2685, 2009.

[25] L. W. Gaber, L. W. Moore, R. R. Alloway et al., "Correlation between Banff classification, acute renal rejection scores and reversal of rejection," Kidney International, vol. 49, no. 2, pp. 481-487, 1996.

[26] L. C. Racusen, K. Solez, and S. Olsen, "Pathology of kidney transplantation," in Kidney Transplant Rejection-Diagnosis and Treatment, L. C. Racusen, K. Solez, and J. F. Burdick, Eds., p. 383, Dekker, New York, NY, USA, 3rd edition, 1998.

[27] R. B. Colvin, “The renal allograft biopsy," Kidney International, vol. 50, no. 3, pp. 1069-1082, 1996. 
[28] H. Noorchashm, A. J. Reed, S. Y. Rostami et al., "B cell-mediated antigen presentation is required for the pathogenesis of acute cardiac allograft rejection," Journal of Immunology, vol. 177, no. 11, pp. 7715-7722, 2006.

[29] H. L. Martins, C. Silva, D. Martini, and I. L. Noronha, "Detection of B lymphocytes $\left(\mathrm{CD} 20^{+}\right)$in renal allograft biopsy specimens," Transplantation Proceedings, vol. 39, no. 2, pp. 432434, 2007.

[30] V. Zarkhin, L. Li, and M. Sarwal, “'To B or not to B?' B-cells and graft rejection," Transplantation, vol. 85, no. 12, pp. 1705-1714, 2008.

[31] O. Viklicky, P. Hribova, H.-D. Volk et al., "Molecular phenotypes of acute rejection predict kidney graft prognosis," Journal of the American Society of Nephrology, vol. 21, no. 1, pp. 173-180, 2010.

[32] P. Sagoo, E. Perucha, B. Sawitzki et al., "Development of a cross-platform biomarker signature to detect renal transplant tolerance in humans," Journal of Clinical Investigation, vol. 120, no. 6, pp. 1848-1861, 2010.

[33] K. A. Newell, A. Asare, A. D. Kirk et al., "Identification of a B cell signature associated with renal transplant tolerance in humans," Journal of Clinical Investigation, vol. 120, no. 6, pp. 1836-1847, 2010.

[34] S. Brouard, E. Mansfield, C. Braud et al., "Identification of a peripheral blood transcriptional biomarker panel associated with operational renal allograft tolerance," Proceedings of the National Academy of Sciences of the United States of America, vol. 104, no. 39, pp. 15448-15453, 2007.

[35] O. Thaunat, N. Patey, C. Gautreau et al., "B cell survival in intragraft tertiary lymphoid organs after rituximab therapy," Transplantation, vol. 85, no. 11, pp. 1648-1653, 2008.

[36] L. K. Kayler, F. G. Lakkis, C. Morgan et al., "Acute cellular rejection with CD20-positive lymphoid clusters in kidney transplant patients following lymphocyte depletion," American Journal of Transplantation, vol. 7, no. 4, pp. 949-954, 2007.

[37] S. M. Bagnasco, W. Tsai, M. H. Rahman et al., "CD20-positive infiltrates in renal allograft biopsies with acute cellular rejection are not associated with worse graft survival," American Journal of Transplantation, vol. 7, no. 8, pp. 1968-1973, 2007.

[38] P. Brændstrup, O. W. Bjerrum, O. J. Nielsen et al., "Rituximab chimeric anti-CD20 monoclonal antibody treatment for adult refractory idiopathic thrombocytopenic purpura," American Journal of Hematology, vol. 78, no. 4, pp. 275-280, 2005.

[39] P. P. Tak and J. R. Kalden, "Advances in rheumatology: new targeted therapeutics," Arthritis Research and Therapy, vol. 13, no. 1, article S5, 2011.

[40] T. D. Shanafelt, H. L. Madueme, R. C. Wolf, and A. Tefferi, "Rituximab for immune cytopenia in adults: idiopathic thrombocytopenic purpura, autoimmune hemolytic anemia, and evans syndrome," Mayo Clinic Proceedings, vol. 78, no. 11, pp. 1340-1346, 2003.

[41] R. A. Sidner, B. K. Book, A. Agarwal, C. M. Bearden, C. A. Vieira, and M. D. Pescovitz, "In vivo human B-cell subset recovery after in vivo depletion with rituximab, anti-human CD20 monoclonal antibody," Human Antibodies, vol. 13, no. 3 , pp. 55-62, 2004.

[42] C. J. Sonnenday, D. S. Warren, M. Cooper et al., "Plasmapheresis, CMV hyperimmune globulin, and anti-CD20 allow ABO-incompatible renal transplantation without splenectomy," American Journal of Transplantation, vol. 4, no. 8, pp. 1315-1322, 2004.
[43] G. Tydén, G. Kumlien, H. Genberg, J. Sandberg, T. Lundgren, and I. Fehrman, "ABO-incompatible kidney transplantation and rituximab," Transplantation Proceedings, vol. 37, no. 8, pp. 3286-3287, 2005.

[44] G. Tydén, G. Kumlien, and I. Fehrman, "Successful ABOincompatible kidney transplantations without splenectomy using antigen-specific immunoadsorption and rituximab," Transplantation, vol. 76, no. 4, pp. 730-731, 2003.

[45] P. Ravichandran, T. Natrajan, and R. Jaganathan, "Combination treatment of low dose Anti-Thymocyte Globulin (ATG), Rituximab and high dose Sirolimus as induction agents in immuneconditioned recipients," International Immunopharmacology, vol. 6, no. 13-14, pp. 1973-1976, 2006.

[46] I. C. Balfour, A. Fiore, R. J. Graff, and A. P. Knutsen, "Use of rituximab to decrease panel-reactive antibodies," Journal of Heart and Lung Transplantation, vol. 24, no. 5, pp. 628-630, 2005.

[47] Y. Yamada, K. Hoshino, Y. Morikawa et al., "Successful liver transplantation across the ABO incompatibility barrier in 6 cases of biliary atresia," Journal of Pediatric Surgery, vol. 41, no. 12, pp. 1976-1979, 2006.

[48] J. M. Aranda Jr., J. C. Scornik, S. J. Normann et al., "Anti-CD20 monoclonal antibody (rituximab) therapy for acute cardiac humoral rejection: a case report," Transplantation, vol. 73, no. 6, pp. 907-910, 2002.

[49] H. E. Garrett Jr., K. Groshart, D. Duvall-Seaman, D. Combs, and R. Suggs, "Treatment of humoral rejection with rituximab," Annals of Thoracic Surgery, vol. 74, no. 4, pp. 1240-1242, 2002.

[50] H. E. Garrett Jr., D. Duvall-Seaman, B. Helsley, and K. Groshart, "Treatment of vascular rejection with rituximab in cardiac transplantation," Journal of Heart and Lung Transplantation, vol. 24, no. 9, pp. 1337-1342, 2005.

[51] I. Kaczmarek, M.-A. Deutsch, S. Sadoni et al., "Successful management of antibody-mediated cardiac allograft rejection with combined immunoadsorption and anti-CD20 monoclonal antibody treatment: case report and literature review," Journal of Heart and Lung Transplantation, vol. 26, no. 5, pp. 511-515, 2007.

[52] S. Faguer, N. Kamar, C. Guilbeaud-Frugier et al., "Rituximab therapy for acute humoral rejection after kidney transplantation," Transplantation, vol. 83, no. 9, pp. 1277-1280, 2007.

[53] H. Genberg, A. Hansson, A. Wernerson, L. Wennberg, and G. Tydén, "Pharmacodynamics of rituximab in kidney allotransplantation," American Journal of Transplantation, vol. 6, no. 10, pp. 2418-2428, 2006. 


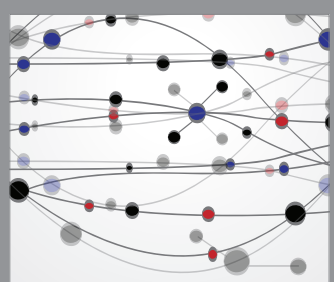

The Scientific World Journal
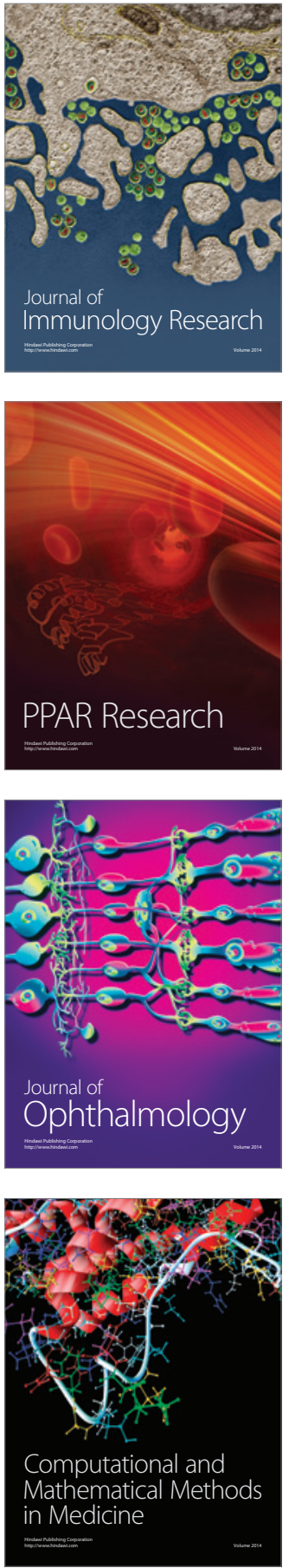

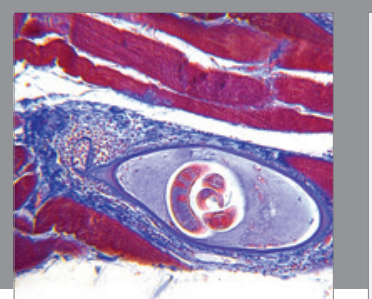

Gastroenterology Research and Practice

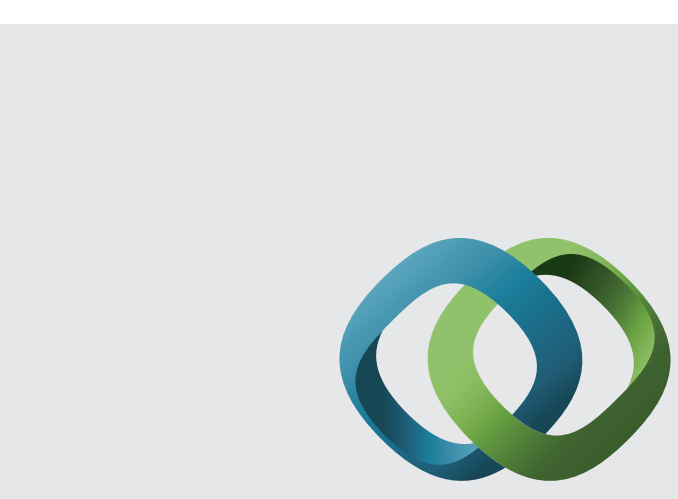

\section{Hindawi}

Submit your manuscripts at

http://www.hindawi.com
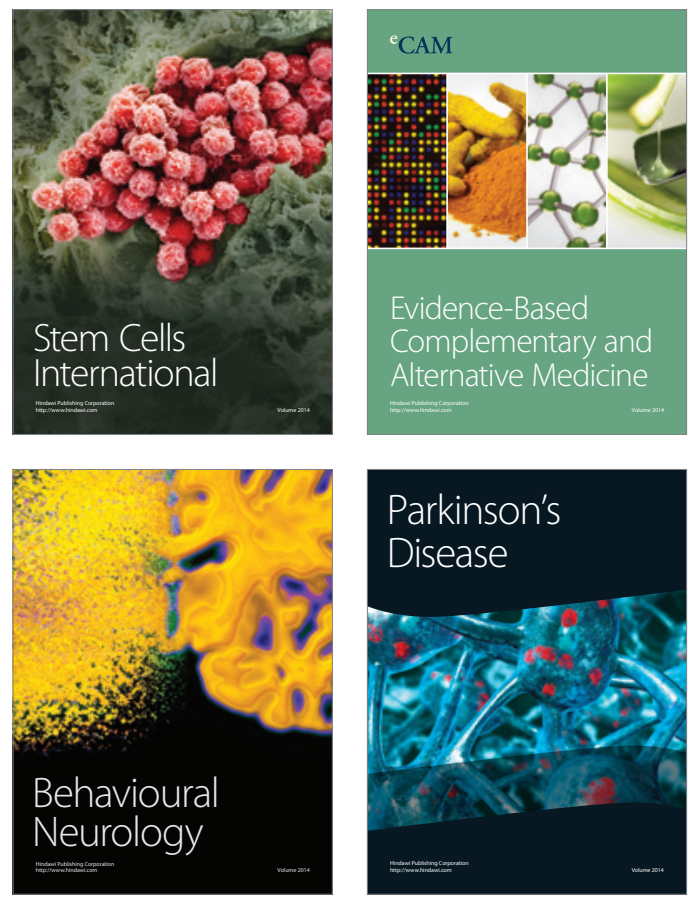
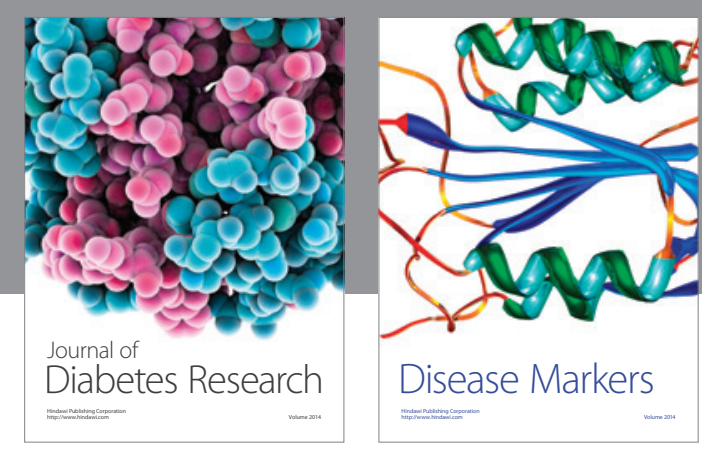

Disease Markers
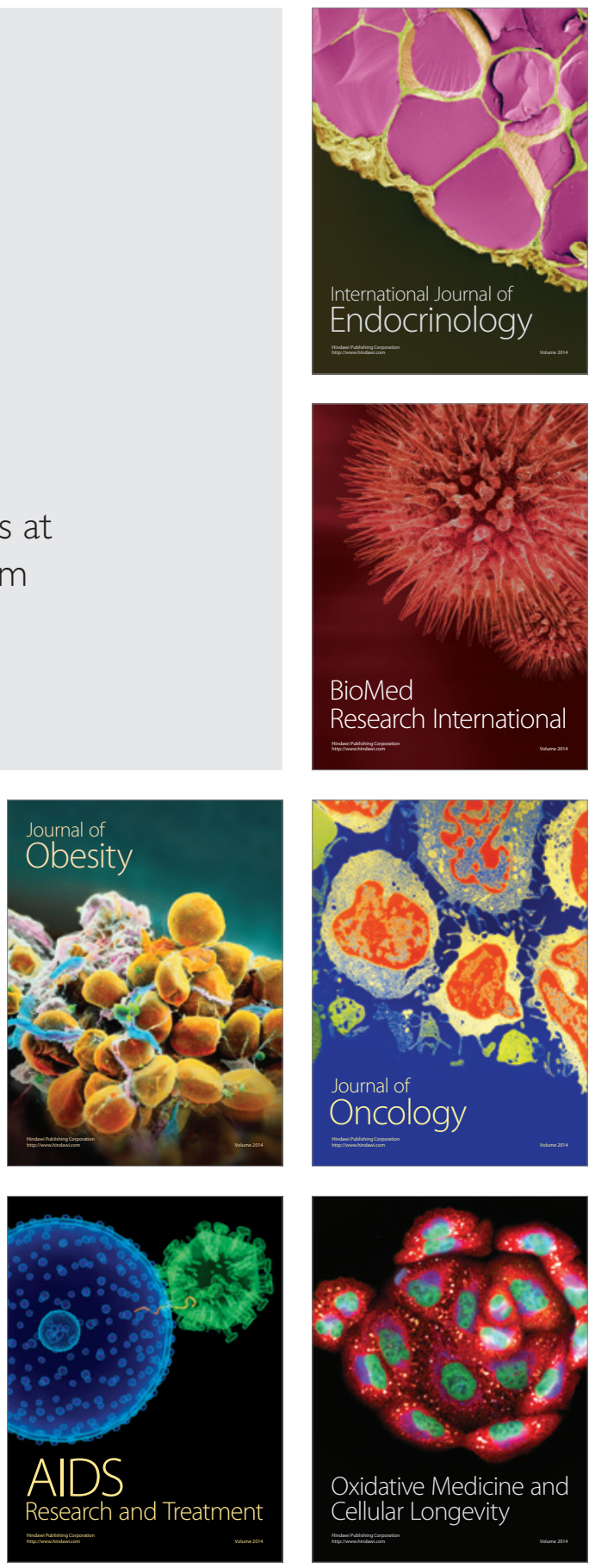